\title{
Expression of Skin Barrier Protein Filaggrin in Skin Diseases without Atopic Dermatitis
}

\author{
Yang Zhang, Chen Tu, Shuang Wang, Shengxiang Xiao* \\ Department of Dermatology, The Second Affiliated Hospital, School of Medicine, Xi'an Jiaotong University, Xi'an, China \\ Email: *Doric2006@163.com
}

How to cite this paper: Zhang, Y., Tu, C., Wang, S. and Xiao, S.X. (2018) Expression of Skin Barrier Protein Filaggrin in Skin Diseases without Atopic Dermatitis. Journal of Biosciences and Medicines, 6, 101-112. https://doi.org/10.4236/jbm.2018.61009

Received: December 19, 2017

Accepted: January 26, 2018

Published: January 29, 2018

Copyright $(9) 2018$ by authors and Scientific Research Publishing Inc. This work is licensed under the Creative Commons Attribution International License (CC BY 4.0).

http://creativecommons.org/licenses/by/4.0/

\section{(c) (i) Open Access}

\begin{abstract}
The epidermis represents an essential barrier versus a broad range of exogenous stimuli. To form a functional epidermis, keratinocytes express filaggrin which plays a vital role in atopic dermatitis. However the relationship between filaggrin and other skin diseases remains unknown. In our study we chose 5 different common skin diseases and analyzed the expression of filaggrin in the skin using immunohistochemistry. Imiquimod (IMQ)-induced mouse model was used for detecting the filaggrin level and barrier function. The results indicated that the expression of filaggrin is reduced in psoriasis compared to the other skin diseases. Furthermore in vivo study showed that the skin barrier is defected with a decreased expression of filaggrin in IMQ-induced psoriasis mouse model, which is accompanied with an increased level of IL-17/IL-23. In conclusion, the defective skin barrier is involved in the development of psoriasis in human and mice with a reduced expression of filaggrin which may be regulated by the increased level of IL-17/IL-23 in the skin.
\end{abstract}

\section{Keywords}

Skin Barrier, Psoriasis, Filaggrin, Atopic Dermatits

\section{Introduction}

The skin, as the largest organ in the body comprising approximately $10 \%$ of body weight, protects the body from dehydration and environmental insults through establishment of the protective epidermal permeability barrier. The epidermal barrier integrates the body's physiology with the terrestrial environment in two paths: one is an inside-out barrier to minimize trans-epidermal water loss and the other works as an outside-in barrier to prevent invasion by infectious agents and toxic substances [1].

There are three musketeers of the epidermal barrier: stratum corneum (SC) as *Corresponding author. 
an air-liquid interface barrier, tight junctions (TJs) as a liquid-liquid interface barrier, and Langerhans cells (LCs) as an immune barrier [2]. During embryonic development, the ectodermal cell layer covering the body develops into a stratified epidermis which is essential at birth and has the ability to confront the arid and toxic postnatal environments [3]. To maintain skin barrier homeostasis requires the delivery of lipids and proteins, which are contained in lamellar granules (keratinosomes) of the granular layer, to the stratum corneum interstices and the formation of high molecular weight polymers through the crosslinking of corneocyte envelope proteins such as loricrin, involucrin, filaggrin and other peptides. The epidermal barrier after birth is mainly regulated by a complex epidermal differentiation program [2].

A defective skin barrier is considered as an important feature of atopic dermatitis (AD), which affects nearly $10 \%$ of the world population [4]. In addition, research on the contribution to skin homeostasis has helped to decipher how the epidermal barrier can be intrinsically changed in other diseases, such as acne vulgaris, ichthyosis vulgaris and allergic disease [5] [6] [7]. More importantly, studies of filaggrin represent us a major advance in the understanding of defective barrier [8]. Loss-of-function mutations in the filaggrin gene (FLG) can not only cause ichthyosis vulgaris, the most common disorder of keratinization, but also a strong genetic risk factor for $\mathrm{AD}$, marked a significant breakthrough in the understanding of $\mathrm{AD}$ pathogenesis. The reported FLG mutations have an equivalent molecular biological effect, since they produce biochemically unstable truncated profilaggrin which cannot be processed to release functional filaggrin [8]. Filaggrin is ultimately degraded on the skin surface to release its component amino acids, which contributes to epidermal hydration and barrier function. Recently, psoriasis has been investigated with respect to a hypothetical $F L G$ association [9]. In addition, Filaggrin, as a major component of keratohyaline granules, is a marker of terminal differentiation of the epidermis. It is also reported that the alert expression of filaggrin occurred in the pathologic human related cancer, pre-cancer and other skin diseases [10] [11]. However, the relationship between skin barrier, filaggrin and skin diseases without atopic diseases remains unknown.

The aim of the present study is to dissect the level of the skin barrier protein filaggrin in the skin diseases without $\mathrm{AD}$, including epidermal cyst, trichilemmal cyst, steatocystoma, sebaceous cyst and psoriasis. The five skin diseases which show epithelial proliferation in some extend are different from each other. Most of them are common skin benign tumors including trichilemmal cysts which arise from the isthmus of the hair follicle, sebaceous cysts which arise from duct obstruction of a sebaceous gland in the hair follicle, epidermal cysts which is one of the common benign tumours presenting anywhere in the body and steatocystoma which is a benign adnexal tumor originating from the pilosebaceous duct junction. Psoriasis is a common chronic inflammatory skin disease which is characterized by epidermal hyperproliferation and altered differentiation. In 
addition using the imiquimod (IMQ)-induced psoriasis mouse model, which was highly used in reported studies [12], to identify the barrier function is defected in the early phase of psoriasis through down regulated filaggrin expression in vivo. Our results indicate that the defective skin barrier is involved in the development of psoriasis with a reduced expression of filaggrin in human and mice.

\section{Materials and Methods}

\subsection{Human Skin Sample}

Bioptic fragment of patient and normal human skin were obtained during aesthetic surgery after written informed consent $(n=5)$. The procedures were in accordance with the ethical standards of the Institutional committee on human experimentation.

\subsection{Animal Preparation}

C57BL/6J mice (from Xi'an Jiaotong University Animal Facility) with 8 weeks old were prepared in both female and male. For the first step, pretreatment for the skin permeability experiments was done and tissue was divided into two groups ( $n=5$ respectively), receiving the following forms of pretreatment prior to the permeability measurements: one group was pretreated for 2 hours with $15 \%$ ethanol and the second group with PBS as control. For the second experiments, a topical dose of $62.5 \mathrm{mg} 5 \%$ IMQ cream (from the second hospital of Xi'an Jiaotong university) was applied daily to the shaved back region of mice, while a non-toxic lanolin-derived occlusion cream was applied as control (CTL) group. IMQ and CTL treatments were carried out for 5 consecutive days and mice were sacrificed on day 6 by cervical dislocation [12]. Mice were observed everyday mainly on the phenotype and clinical lesions. Symptoms were evaluated by skin erythema and lichen. Each symptom was graded from 0 to 3 (no symptoms $=0$; mild $=1$; moderate $=2$; and severe $=3$ ). The sum of these individual scores was taken as the overall clinical score [12]. At the end of the day skin biopsy was performed and the infiltrated inflammatory cells were measured using immunofluorescence.

\subsection{Immunohistochemistry}

Paraffin-embedded samples were prepared and sections were blocked with $4 \%$ BSA for $20 \mathrm{mins}$ in $37^{\circ} \mathrm{C}$. For immunohistochemistry (IHC) against filaggrin, a ratanti-human monoclonal antibody (Abcam, 1:100), a biotinylated secondary goat anti-rat antibody before analysis by light microscopy. Skin biopsies $(n=5)$ from patients without $\mathrm{AD}$ and normal human skin $(n=5)$ served as control samples.

\subsection{Vascular Permeability Assay}

Evans blue dye (25 $\mu \mathrm{g} / \mathrm{g}$ weight in PBS; Sigma) was injected intraperitoneally 
with 8 week-old mice. After 2 hours, the mice were euthanized and ears were removed and weighed. The Evans blue dye was extracted from the ears with formamide $(0.5 \mathrm{ml} / 100 \mathrm{mg}$ tissue $)$ overnight at $55^{\circ} \mathrm{C}$ and measured spectrophotometrically at $620 \mathrm{~nm}$. Determine protein concentration of the protein and the evans blue extravasation is expressed as relative OD $620 \mathrm{~nm} / \mathrm{mg}$ protein [13] [14].

\subsection{FITC-Conjugated Albumin Permeability Assay}

Ear skin was exposed to Fluorescein isothiocyanate (FITC) labelled albumin ( $0.5 \%$; Sigma) for 2 hours, and the tissue was fixed in $10 \%$ formalin and processed in paraffine. Sections $(7 \mathrm{~mm})$ were cut and examined by fluorescencemicroscopy.

\subsection{Western Blot Analysis}

Skin tissue lysis was added to $5 \times$ SDS sample buffer and boiled for 3 minutes. Samples were resolved by SDS PAGE (10\% polyacrylamide concentration) and transferred by electrophoresis onto a nitrocellulose membrane. After blocking, membrane was incubated with primary anti-mouse filaggrin antibody (Santa Cruz), followed by secondary antibody. A chemiluminescent Western blotting detection kit was used according to the manufacturer's protocol to visualize the labeled protein.

\subsection{Immunofluorescence}

The skin sample was processed in OCT. Cryostat sections were air-dried, blocked with PBS containing 10\% of normal goat serum for 5 mins after incubate with primary antibody $4^{\circ} \mathrm{C}$ overnight and then stained with secondary antibody for 1 hour at room temperature. Photos were taken under immunofluorescence microscope.

\subsection{Statistical Analysis}

The data are expressed as Mean \pm SE and were analyzed using the Student's $t$-test. A $p$ value less than 0.05 was considered significant.

\section{Results}

\subsection{Filaggrin Expression in the Skin Diseases without AD}

The patients we examined with filaggrin expression included psoriasis and benign skin tumor, such as epidermal cysts, trichilemmal cyst, steatocystoma, sebaceous cyst (Table 1). As expected, the normal skin tissue displayed filaggrin expression in thestratum corneum (SC). Interestingly, all the skin specimens from psoriasis were negative for filaggrin, while the benign skin tumor remains similar with normal skin tissue (Figure 1). These results indicate that the skin barrier protein filaggrin is reduced in the psoriasis patients compared to normal healthy skin. 


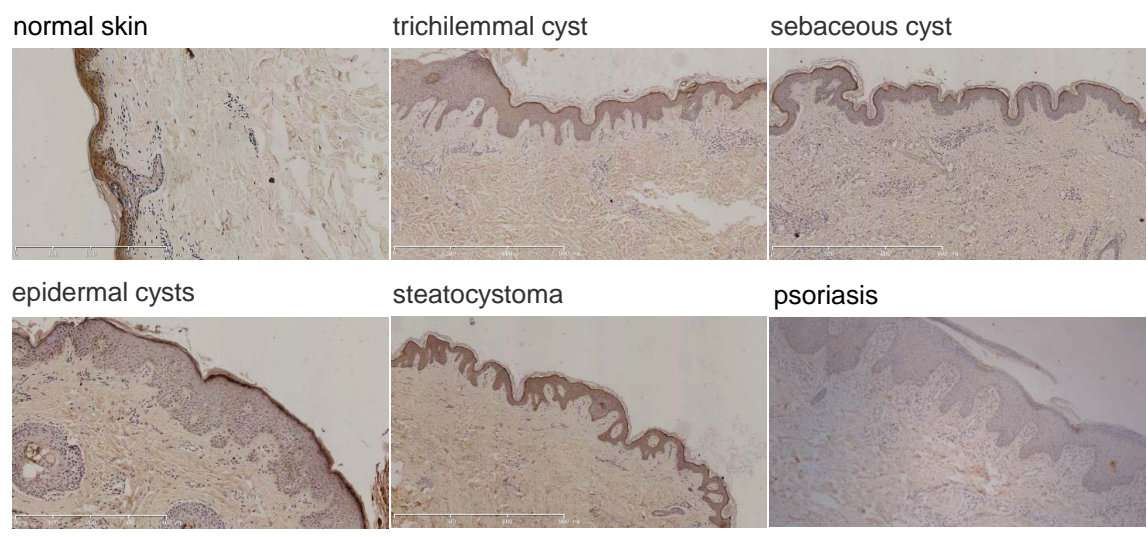

Figure 1. The expression of filaggrin was reduced mainly in the psoriasis compared to the other skin diseases and healthy skin using immunohistochemistry assay: In the normal skin, the expression of filaggrin mainly located in the SC of skin. All the psoriasis patients $(n=5)$ exhibited that the staining of filaggrin in the skin were negative, while the expression of filaggrin in SC of the skin was similar to the normal skin in patients with trichilemmal cyst, sebaceous cyst, epidermal cysts and steatocystoma. SC: stratum corneum.

Table 1. List patients of involved in this study.

\begin{tabular}{|c|c|c|c|c|c|c|}
\hline $\begin{array}{l}\text { Patient } \\
\text { (number) }\end{array}$ & $\begin{array}{l}\text { Histological } \\
\text { diagnosis }\end{array}$ & $\begin{array}{l}\text { Key feature } \\
\text { (arise from) }\end{array}$ & $\begin{array}{c}\text { Female } \\
\text { (number) }\end{array}$ & $\begin{array}{c}\text { Male } \\
\text { (number) }\end{array}$ & Age & $\begin{array}{c}\text { Filaggrin } \\
\text { IHC }\end{array}$ \\
\hline $\mathrm{n}=5$ & Healthy people & normal skin & 2 & 3 & $15-45$ & $\mathrm{SC}(+)$ \\
\hline $\mathrm{n}=5$ & Trichilemmalcyst & hair follicle & 2 & 3 & $30-45$ & $\begin{array}{l}\text { SC (+); } \\
\text { cyst (+) }\end{array}$ \\
\hline $\mathrm{n}=5$ & Sebaceous cyst & sebaceous gland & 1 & 4 & $15-35$ & $\mathrm{SC}(+)$ \\
\hline $\mathrm{n}=5$ & Epidermal cyst & epidermoid cyst & 2 & 3 & $25-37$ & $\begin{array}{l}\text { SC (+); } \\
\text { cyst }(+)\end{array}$ \\
\hline $\mathrm{n}=5$ & Steatocystoma & $\begin{array}{l}\text { pilosebaceous } \\
\text { duct junction }\end{array}$ & 1 & 4 & $20-34$ & $\begin{array}{l}\text { SC (+); } \\
\text { cyst (+) }\end{array}$ \\
\hline $\mathrm{n}=5$ & Psoriasis & $\begin{array}{c}\text { chronic } \\
\text { inflammatory }\end{array}$ & 2 & 3 & $25-36$ & SC $(-)$ \\
\hline
\end{tabular}

\subsection{IMQ-Induced Psoriasis Animal Model}

In order to convince the skin barrier is involved in the development of psoriasis, we used imiquimod-induced mouse model as reported to figure out the relationship between skin barrier and psoriasis. Mouse back skin was treated with $62.5 \mathrm{mg} 5 \%$ IMQ or a non-toxic cream once per day for five consecutive days. From the third day the erythema and scaling of IMQ-treated mice were observed which is similar to the reported study [12] (Figure 2(a)). Also the clinical score index is significant higher than control mice (Figure $2(\mathrm{~b})$ ). Since psoriasis mouse model exhibits an infiltration of inflammatory cells, which was mainly composed of neutrophils and $\mathrm{T}$ cells. Using immunofluorescence assay, neutrophils, $\mathrm{T}$ cells and mast cells were detected using ly6g, CD3 and toluidine blue staining respectively (Figure $2(\mathrm{c})$ ). Furthermore, the IL-17 and IL-23 were 


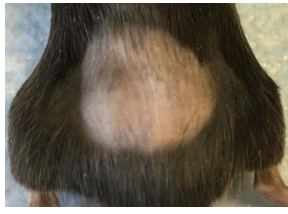

control

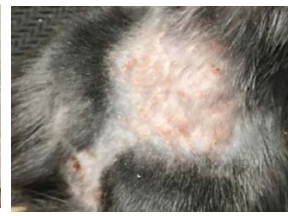

IMQ

(a)

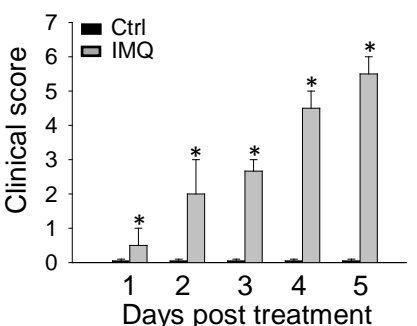

(b)

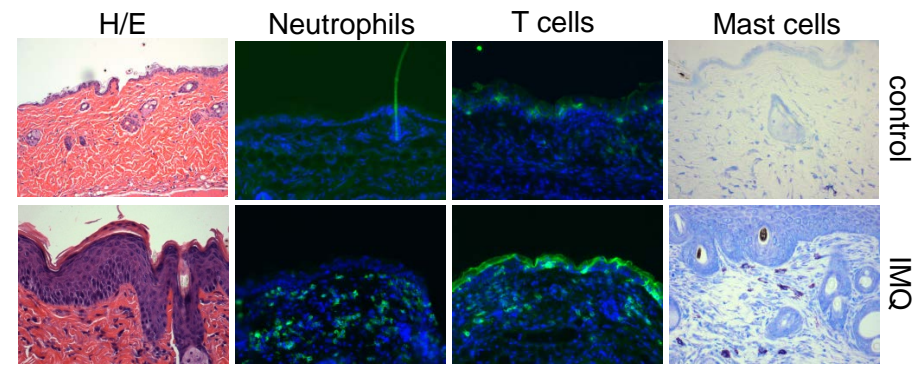

(c)

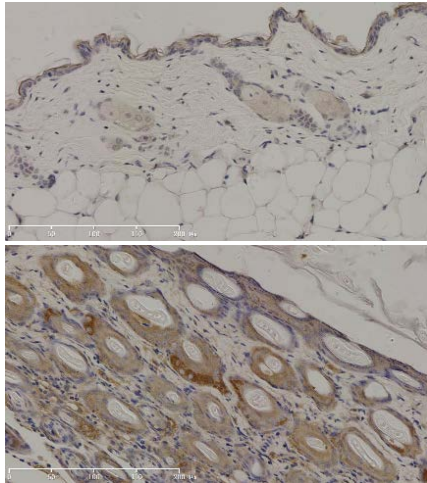

IL-17

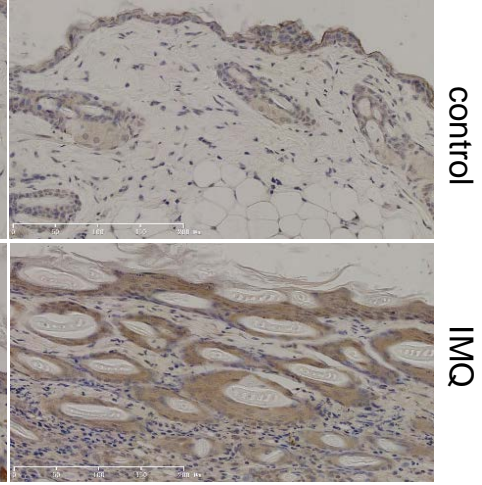

IL-23

(d)

Figure 2. The phenotype of IMQ-induced dermatitis: (a) Phenotype of the normal mice and IMQ-treated mice at the 3rd day after treatment; (b) The clinical score of normal mice and IMQ-treated mice, $P<0.05$; (c) H/E staining, Neutrophil staining using Iy6g antibody; T cell staining using CD3 antibody and mast cells staining using Toluidine blue staining; (d) IL-17 and IL-23 level were analyzed by immunohistochemistry method and results showed that the level of IL-17 and IL-23 in IMQ-induced psoriasis model was increased compare to the negative control mice. Original magnification $\times 200$.

increased in IMQ-treated mice compared to the control mice using immunohistochemistry assay (Figure $2(\mathrm{~d})$ ). Together with the reported studies, a psoriasis mouse model was successfully induced.

\subsection{Defective Skin Barrier in Psoriasis Mouse Model}

In order to confirm the defective skin barrier is involved in psoriasis, IMQ-induced mouse model was used in our study. Here we measured the skin barrier in IMQ-psoriasis mouse model using evans blue extravasation assay and albumin assay. 
Firstly, in order to convince the efficiency of these two methods as an accurate way to evaluate the skin barrier. We use a short term application of ethanol to defect the skin barrier as reported [15]. As to vesicular permeability assay, the OD reading per $1 \mathrm{mg}$ protein in ethanol-treated ear was significantly higher than PBS-treated ear (Figure 3(a)). And albumin penetration assay, skin tissue typically showed a thin, bright line of albumin fluorescence along the epithelial surface in the PBS group, the rest of the epithelium appearing dark. While in ethanol group in general, hadan intercellular distribution of albumin fluorescence extending deeper into the epithelium, but some of them only maintain a light spot in the deep epithelium cells (Figure 3(b)). This results showed that evans blue extravasation assay and albumin assay are able to evaluate the barrier permeability accurately.

As to IMQ-induced psoriasis mouse model, the evans blue extravasation was significant higher in IMQ treated group compared to negative control group $(P<0.05)$ (Figure 4(a)). The albumin penetration reached to the deeper epithelium while the negative control mice only passaged in the surface of the skin (Figure 4(b)). In addition, filaggrin expression was analyzed using western blot. The results showed that mature filaggrin expression in IMQ treated group is reduced compared to the negative control group (Figure 4(c)).

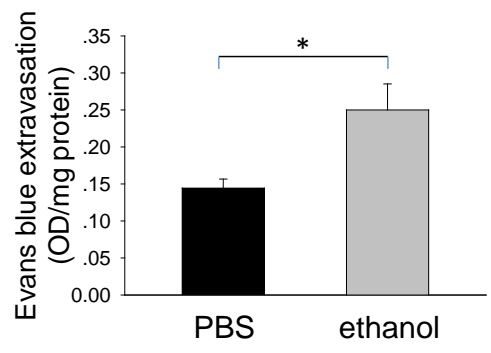

(a)

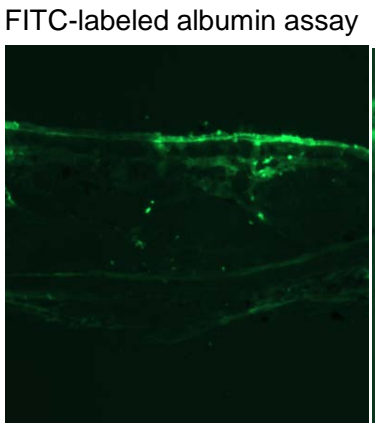

PBS-treated

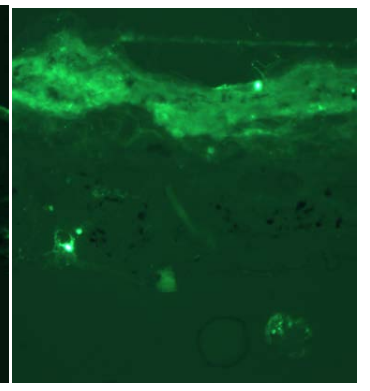

ethanol-treated

(b)

Figure 3. Ethanol-induced skin barrier disruption was assayed using evans blue extravasation and fitc-labeled albumin assay. (a): Inside-out barrier function analyzed by Evans blue extravasation; (b): Outside-in barrier function analyzed by FITC-conjuncted albumin assay; both of the results showed that the barrier was defected in ethanol-induced barrier disruption compared to the negative control mice which indicated that these two methods are able to evaluate the skin barrier function accurately, $n=4, P<0.05$. 


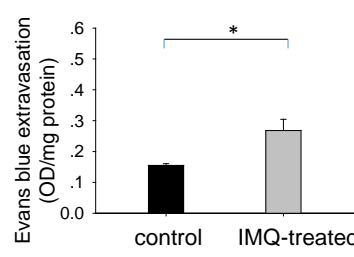

(a)

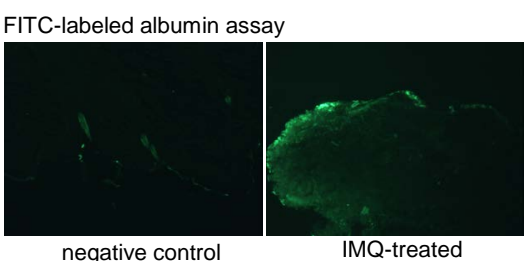

(b)

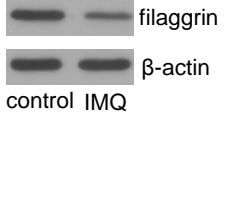

(c)

Figure 4. Defective skin barrier is involved in IMQ-induced dermatitis with a reduced expression of filaggrin. (a) Inside-out barrier function analyzed by Evans blue extravasation; (b) Outside-in barrier function analyzed by FITC-conjuncted albumin assay; both of them indicated that the barrier function of IMQ-treated mice was defected compared to the negative control mice, $n=5, P<0.05$; (c) Expression of filaggrin in IMQ treated mice was induced compare to the negative control mice by western blot.

In a summary, the defective of skin barrier is involved in the psoriasis with an alert expression of filaggrin in human and mouse model.

\section{Discussion}

Several skin disorders are associated with impaired skin barrier function, such as atopic dermatitis and other inflammatory skin diseases [4]. Psoriasis is a common, inflammatory, chronic and relapsing skin disease with a prevalence of $1 \%$ $4 \%$ [16]. It is characterized by an abnormal keratinocyte proliferation and parakeratosis with vascular hyperplasia and infiltration of inflammatory cells into the dermis and epidermis. The pathogenesis of psoriasis is multifactorial. A genetic predisposition appears to play a pivotal role in the susceptibility to develop psoriasis. It is reported that there is an association between psoriasis and $F L G$ because of its co-association with the 1q21 locus in genome-wide scans [9]. And also recent studies revealed that vitamin $\mathrm{D}$ is involved in the tissue barriers and its receptor may create a pro-inflammatory environment and alteration of the barrier integrity that may favor the development of psoriatic lesions after exposure to external triggers [17] [18]. In our study, we chose five different skin diseases except atopic dermatitis, the results highlight that the filaggrin expression in the epithelia from psoriasis patients is reduced compared to the normal healthy skin. Filaggrin, a histidine-rich protein which can be degraded to free amino acids by caspase-14, plays a vital role in maintaining the hydration of the stratum corneum and epidermal homeostasis [19] [20].

The exact etiology of psoriasis remains unclear but recent evidence suggests the crucial role of active T-cells and cytokines in the inflammatory cascade [16]. There is research evidence indicate that the vital role of IL-23/IL-17A cytokines in the development of the disease [21] [22]. Apart from this, the defective skin barrier may occur and alter the structure and function of skin [23]. In our study also revealed that the skin barrier protein filaggrin is reduced in the psoriasis patients, although as a long time impaired barrier function was regarded as a vital pathogenesis in atopic dermatitis (AD) [2]. In order to convince these results we use the IMQ-induced psoriasis mouse model [12]. IMQ is a TLR-7/8 agonist and 
a potent immune activator used for the treatment of actinic keratosis and superficial basal cell carcinomas [24]. As a side effect, it can induce psoriasis-like skin flares in predisposed humans [25]. Interestingly, some patients using IMQ may suffer from eczema and bullous pemphigoid-liked side effects [26] [27] [28]. Daily topical application of IMQ on mice leads to a psoriasis-like dermatitis with many hallmarks of human psoriasis which depends on IL-23/IL-17 axis [29]. It is reported that IL-17 down-regulates the expression of FLG as well as the genes that encode filaggrin processing enzymes in cultured keratinocytes [30]. And also recently it is found that caspase-14 deficiency is prone to develop psoriasis in mouse model study [31]. The defective skin barrier may impact the host microbial homeostasis through vitamin $\mathrm{D}$ or VDR which involves appropriate immune regulation [32] [33]. In our study, we used two different methods to measure the skin barrier of IMQ-induced psoriasis-like dermatitis on mice and the results indicate that the defective skin barrier including inside-out and outside-in barrier function is involved in the development of psoriasis in mice. Furthermore, the reduced expression of filaggrin with an increased level of IL-17/IL-23 inIMQ-induced mice was showed compared to the control mice. The reduced filaggrin may be suppressed by the increased level of IL-17/IL-23. The future step of our study will focus on the mechanism of reduced filaggrin in psoriasis and other functions of filaggrin in the pathogenesis of psoriasis.

\section{Acknowledgements}

The authors would like to thank the department of dermalpathology in the Second Affiliated Hospital for collecting the skin tissue and also thank for the members of our department to give me so many good suggestions during my experiments.

\section{Financial Support}

This research did not receive any specific grant from funding agencies in the public, commercial, or not-for-profit sectors.

\section{References}

[1] Ross, F.P. and Christiano, A.M. (2006) Nothing but Skin and Bone. Journal of Clinical Investigation, 116, 1140-1149. https://doi.org/10.1172/JCI28605

[2] Kubo, A., Nagao, K. and Amagai, M. (2012) Epidermal Barrier Dysfunction and Cutaneous Sensitization in Atopic Diseases. Journal of Clinical Investigation, 122, 440-447. https://doi.org/10.1172/JCI57416

[3] Indra, A.K. and Leid, M. (2011) Epidermal Permeability Barrier Measurement in Mammalian Skin. Methods in Molecular Biology, 763, 73-81.

https://doi.org/10.1007/978-1-61779-191-8_4

[4] Schmuth, M., Blunder, S., Dubrac, S., Gruber, R. and Moosbrugger-Martinz, V. (2015) Epidermal Barrier in Hereditary Ichthyoses, Atopic Dermatitis, and Psoriasis. Journal der Deutschen Dermatologischen Gesellschaft, 13, 1119-1123. https://doi.org/10.1111/ddg.12827 
[5] Egawa, G. and Kabashima, K. (2018) Barrier Dysfunction in the Skin Allergy. Allergology International, 67, 3-11. https://doi.org/10.1016/j.alit.2017.10.002

[6] Rocha, M.A. and Bagatin, E. (2017) Skin Barrier and Microbiome in Acne. Archives of Dermatological Research, 1-5. https://doi.org/10.1007/s00403-017-1795-3

[7] Chen, H., Ho, J.C., Sandilands, A., Chan, Y.C., Giam, Y.C., Evans, A.T., Lane, E.B. and Mclean, W.H.(2008) Unique and Recurrent Mutations in the Filaggrin Gene in Singaporean Chinese Patients with Ichthyosis Vulgaris. Journal of Investigative Dermatology, 128, 1669-1675. https://doi.org/10.1038/jid.2008.2

[8] Brown, S.J. and Mclean, W.H. (2012) One Remarkable Molecule: Filaggrin. Journal of Investigative Dermatology, 132, 751-762. https://doi.org/10.1038/jid.2011.393

[9] Bowcock, A.M., Shannon, W., Du, F., Duncan, J., Cao, K., Aftergut, K., Catier, J., Fernandez-Vina, M.A. and Menter, A. (2001) Insights into Psoriasis and Other Inflammatory Diseases from Large-Scale Gene Expression Studies. Human Molecular Genetics, 10, 1793-1805. https://doi.org/10.1093/hmg/10.17.1793

[10] Skaaby, T., Husemoen, L.L., Jorgensen, T., Johansen, J.D., Menne, T., Szecsi, P.B., Stender, S., Bager, P., Thyssen, J.P. and Linneberg, A. (2014) Associations of Filaggrin Gene Loss-of-Function Variants and Human Papillomavirus-Related Cancer and Pre-Cancer in Danish Adults. PLoS One, 9, e99437.

https://doi.org/10.1371/journal.pone.0099437

[11] Makino, T., Mizawa, M., Inoue, S., Noguchi, M. and Shimizu, T. (2016) The Expression Profile of Filaggrin-2 in the Normal and Pathologic Human Oral Mucosa. Archives of Dermatological Research, 308, 213-217.

https://doi.org/10.1007/s00403-016-1627-x

[12] Swindell, W.R., Michaels, K.A., Sutter, A.J., Diaconu, D., Fritz, Y., Xing, X., Sarkar, M.K., Liang, Y., Tsoi, A., Gudjonsson, J.E. and Ward, N.L. (2017) Imiquimod Has Strain-Dependent Effects in Mice and Does Not Uniquely Model Human Psoriasis. Genome Medicine, 9, 24. https://doi.org/10.1186/s13073-017-0415-3

[13] Dreymueller, D., Martin, C., Kogel, T., Pruessmeyer, J., Hess, F.M., Horiuchi, K., Uhlig, S. and Ludwig, A. (2012) Lung Endothelial ADAM17 Regulates the Acute Inflammatory Response to Lipopolysaccharide. EMBO Molecular Medicine, 4, 412-423. https://doi.org/10.1002/emmm.201200217

[14] Han, H., Thelen, T.D., Comeau, M.R. and Ziegler, S.F. (2014) Thymic Stromal Lymphopoietin-Mediated Epicutaneous Inflammation Promotes Acute Diarrhea and Anaphylaxis. Journal of Clinical Investigation, 124, 5442-5452. https://doi.org/10.1172/JCI77798

[15] Howie, N.M., Trigkas, T.K., Cruchley, A.T., Wertz, P.W., Squier, C.A. and Williams, D.M. (2001) Short-Term Exposure to Alcohol Increases the Permeability of Human Oral Mucosa. Oral Diseases, 7, 349-354. https://doi.org/10.1034/j.1601-0825.2001.00731.x

[16] Mattozzi, C., Paolino, G., Richetta, A.G. and Calvieri, S. (2016) Psoriasis, Vitamin D and the Importance of the Cutaneous Barrier's Integrity: An Update. The Journal of Dermatology, 43, 507-514. https://doi.org/10.1111/1346-8138.13305

[17] Sigmundsdottir, H., Pan, J., Debes, G.F., Alt, C., Habtezion, A., Soler, D. and Butcher, E.C. (2007) DCs Metabolize Sunlight-Induced Vitamin D3 to "Program" T Cell Attraction to the Epidermal Chemokine CCL27. Nature Immunology, 8, 285-293. https://doi.org/10.1038/ni1433

[18] Richetta, A.G., Silvestri, V., Giancristoforo, S., Rizzolo, P., D’epiro, S., Graziano, V., Mattozzi, C., Navazio, A.S., Campoli, M., D’amico, C., Scarno, M., Calvieri, S. and Ottini, L. (2014) A-1012G Promoter Polymorphism of Vitamin D Receptor Gene Is 
Associated with Psoriasis Risk and Lower Allele-Specific Expression. DNA and Cell Biology, 33, 102-109. https://doi.org/10.1089/dna.2013.2217

[19] Denecker, G., Hoste, E., Gilbert, B., Hochepied, T., Ovaere, P., Lippens, S., Van Den Broecke, C., Van Damme, P., D’herde, K., Hachem, J.P., Borgonie, G., Presland, R.B., Schoonjans, L., Libert, C., Vandekerckhove, J., Gevaert, K., Vandenabeele, P. and Declercq, W. (2007) Caspase-14 Protects against Epidermal UVB Photodamage and Water Loss. Nature Cell Biology, 9, 666-674. https://doi.org/10.1038/ncb1597

[20] Hvid, M., Johansen, C., Deleuran, B., Kemp, K., Deleuran, M. and Vestergaard, C. (2011) Regulation of Caspase 14 Expression in Keratinocytes by Inflammatory Cytokines-A Possible Link between Reduced Skin Barrier Function and Inflammation? Experimental Dermatology, 20, 633-636.

https://doi.org/10.1111/j.1600-0625.2011.01280.x

[21] Grine, L., Dejager, L., Libert, C. and Vandenbroucke, R.E. (2015) An Inflammatory Triangle in Psoriasis: TNF, Type I IFNs and IL-17. Cytokine \& Growth Factor Reviews, 26, 25-33. https://doi.org/10.1016/j.cytogfr.2014.10.009

[22] Galluzzo, M., Talamonti, M., D’adamio, S. and Bianchi, L. (2017) Pharmacokinetic Drug Evaluation of Brodalumab for the Treatment of Psoriasis. Expert Opinion on Drug Metabolism \& Toxicology, 13, 679-691. https://doi.org/10.1080/17425255.2017.1325874

[23] Donetti, E., Cornaghi, L., Arnaboldi, F., Ricceri, F., Pescitelli, L., Maiocchi, M., Carriero, F., Baruffaldi Preis, F. and Prignano, F. (2017) Epidermal Barrier Reaction to an in Vitro Psoriatic Microenvironment. Experimental Cell Research, 360, 180-188. https://doi.org/10.1016/j.yexcr.2017.09.004

[24] Hanna, E., Abadi, R. and Abbas, O. (2016) Imiquimod in Dermatology: An Overview. International Journal of Dermatology, 55, 831-844. https://doi.org/10.1111/ijd.13235

[25] Patel, U., Mark, N.M., Machler, B.C. and Levine, V.J. (2011) Imiquimod 5\% Cream Induced Psoriasis: A Case Report, Summary of the Literature and Mechanism. British Journal of Dermatology, 164, 670-672. https://doi.org/10.1111/j.1365-2133.2010.10124.x

[26] Drummond, A., Pichler, J., Argenziano, G., Zalaudek, I., Longo, C., Lallas, A., Piana, S. and Moscarella, E. (2015) Lichen Planopilaris after Imiquimod 5\% Cream for Multiple BCC in Basal Cell Naevus Syndrome. Australasian Journal of Dermatolo$g y$, 56, e105-e107. https://doi.org/10.1111/ajd.12151

[27] Taylor, C.L., Maslen, M. and Kapembwa, M. (2006) A Case of Severe Eczema Following Use of Imiquimod 5\% Cream. Sexually Transmitted Infections, 82, 227-228. https://doi.org/10.1136/sti.2005.018226

[28] Cavicchini, S., Vezzoli, P., Muratori, S. and Gianotti, R. (2009) Morbilliform Exanthem Induced by Imiquimod in a Patient with Drug-Related Immunosuppression. Clinical and Experimental Dermatology, 34, 526-527. https://doi.org/10.1111/j.1365-2230.2008.02971.x

[29] Rabeony, H., Pohin, M., Vasseur, P., Petit-Paris, I., Jegou, J.F., Favot, L., Frouin, E., Boutet, M.A., Blanchard, F., Togbe, D., Ryffel, B., Bernard, F.X., Lecron, J.C. and Morel, F. (2015) IMQ-Induced Skin Inflammation in Mice Is Dependent on IL-1R1 and MyD88 Signaling But Independent of the NLRP3 Inflammasome. European Journal of Immunology, 45, 2847-2857. https://doi.org/10.1002/eji.201445215

[30] Hanel, K.H., Cornelissen, C., Luscher, B. and Baron, J.M. (2013) Cytokines and the Skin Barrier. International Journal of Molecular Sciences, 14, 6720-6745. https://doi.org/10.3390/ijms14046720 
[31] Hoste, E., Denecker, G., Gilbert, B., Van Nieuwerburgh, F., Van Der Fits, L., Asselbergh, B., De Rycke, R., Hachem, J.P., Deforce, D., Prens, E.P., Vandenabeele, P. and Declercq, W. (2013) Caspase-14-Deficient Mice Are More Prone to the Development of Parakeratosis. Journal of Investigative Dermatology, 133, 742-750. https://doi.org/10.1038/jid.2012.350

[32] Assa, A., Vong, L., Pinnell, L.J., Avitzur, N., Johnson-Henry, K.C. and Sherman, P.M. (2014) Vitamin D Deficiency Promotes Epithelial Barrier Dysfunction and Intestinal Inflammation. The Journal of Infectious Diseases, 210, 1296-1305. https://doi.org/10.1093/infdis/jiu235

[33] Wu, S., Liao, A.P., Xia, Y., Li, Y.C., Li, J.D., Sartor, R.B. and Sun, J. (2010) Vitamin D Receptor Negatively Regulates Bacterial-Stimulated NF-kappaB Activity in Intestine. American Journal of Pathology, 177, 686-697.

https://doi.org/10.2353/ajpath.2010.090998 